\title{
Research on the full life cycle management of the substation Engineering based on Three-Dimensional
}

\author{
Hailiang $\mathrm{Wu}^{1 *}$, Lin Xing ${ }^{1}$, Zhong Liu ${ }^{1}$, Wuchen Zhang ${ }^{1}$, Nan Cheng ${ }^{1}$, Yamin Wang ${ }^{1}$ and Jizhi Su${ }^{1}$ \\ ${ }^{1}$ State Grid Hebei Economic Research Institute, Shijiazhuang, Hebei, 050000, China
}

\begin{abstract}
With the development of modern information technology, the three-dimensional design technology is widely applied in the substation engineering design of State Grid Corporation of China, and will run through the whole process of the power grid, effectively promoting the management of the substation engineering full life cycle.This paper analyzes the application scope of three-dimensional design in substation engineering is studied in depth, and the future application development is prospected, which provides a reference for the development direction of three-dimensional design in the future.
\end{abstract}

\section{Introduction}

In 2018, State Grid Corporation of China will fully implement three-dimensional (3D) design in power transmission and transformation projects of $35 \mathrm{kV}$ and above. First, in order to promote the progress of design technology, realize digital and visual design and combine design with virtual reality technology. Second, to build digital power grid, realize the goal of unifying basic data of power grid, improving construction management level and serving production operation management. Through the 3D digital design of substation project, the design quality and efficiency of substation can be greatly improved[1].

The design data and engineering data information in the $3 \mathrm{D}$ design process will be digitized and transferred to the project management unit and production operation and maintenance unit, and the data information will run through the design, construction, operation, maintenance and decommissioning of power grid engineering, which could lay a solid foundation for promoting the full life cycle management of substation engineering.

\section{Application scope of 3D design of substation engineering}

The key of project life cycle management is the flow and sharing of project data information in each stage of the project. The source of the full life cycle is design, in the era of information design, the design stage is not only the completion of routine design work, but also the establishment process of the whole project data and information. Without the information of design, there will be no digital handover, and the full life cycle management of the project cannot be realized [2].

Therefore, the three-dimensional design of substation engineering should be thoroughly studied and applied in all stages of engineering.

\subsection{Feasibility Study phase}

The feasibility stage focuses on the application of geoscient information[3], and makes use of geographic information system, survey data and hydrological information data to assist decision-making on substation site selection and bulk transportation scheme.

\subsection{Preliminary design stage}

In order to carry out the preliminary design of the engineering project more accurately, this phase uav tilt photography can be used for aerial photography of substation site area, then the high resolution 3D model based on image texture is generated by 3D design software, the precise environment space is established for the substation and line outlet design in the preliminary design stage.

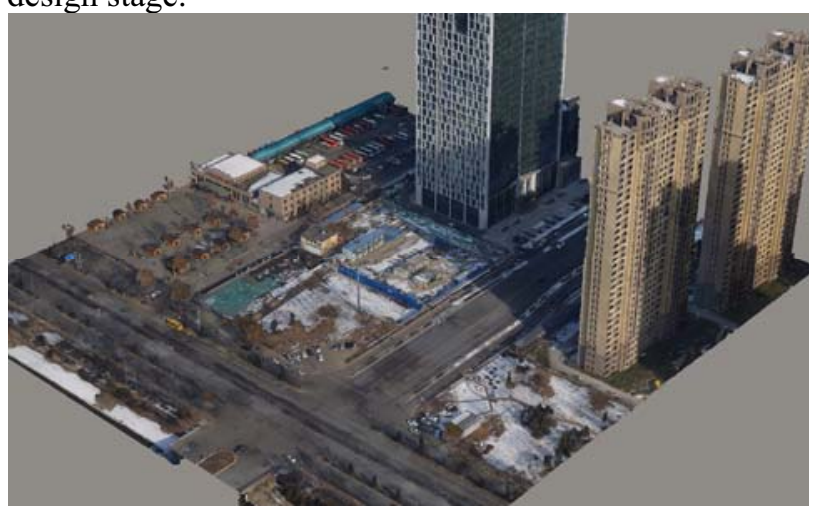

Figure 1. Real 3D model

The three-dimensional design platform of substation is constructed, which centered on a large network database containing model libraries and standardization

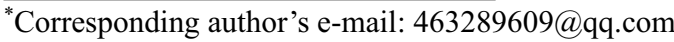


solutions, With the help of 3D design and intelligent correlation mechanism of data, the multi-professional collaborative design of electrical, structure, building, hydraulic, HVAC and general drawing in the same substation project is realized. On the basis of the general design scheme, by means of soft and hard collision check and electric distance check, the general layout, the site and the structure of distribution unit of each voltage grade are optimized to avoid design errors and improve design efficiency fundamentally.

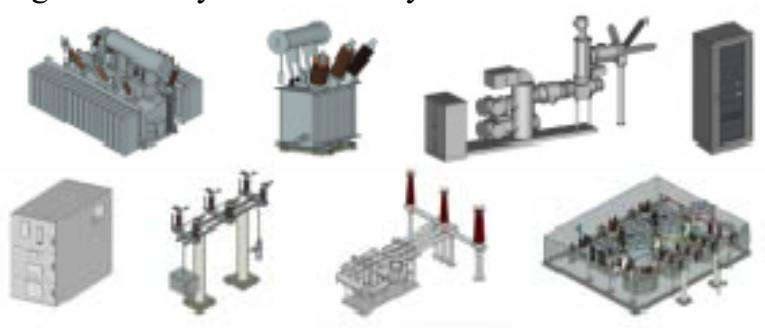

Figure 2.Electrical equipment model

\subsection{Construction documents design phase}

In the stage of construction documents design phase, all majors carry out collaborative design based on the same 3D design platform. According to the equipment drawings provided by the manufacturer, the electrical specialty establishes the model, assigns the electrical equipment parameters, and carries out the design work such as the conventional short-circuit current calculation, wire tension test and battery capacity calculation. Building, structure, hydraulic engineering, HVAC each specialized area carries out the modeling work of wall, gate, building, structure and underground facilities. After the completion of all professional models, 2D flat section drawings are generated by cutting 3D models, and complete the drawing work of main construction drawing volumes and realize automatic material quantity statistics. Finally, through 3D rendering, output the overall rendering effect and 3D animation of substation to show the $3 \mathrm{D}$ panorama of substation.

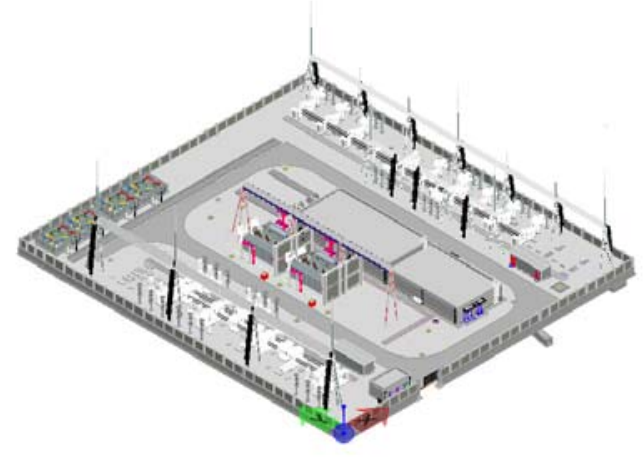

Figure 3. Substation three-dimensional model

\subsection{Engineering construction stage}

The 3D design software could simulate the key construction processes such as assembly building hoisting, electrical equipment installation and structure hoisting, so as to judge the existing problems in the construction in advance, select reasonable construction machinery, optimize the construction scheme and improve the installation efficiency. Ipad and other mobile terminals are used to view 3D models and complete design disclosure, which enables construction unit personnel to have an intuitive and accurate grasp of specific engineering details and practices, so as to improves the efficiency and quality of design disclosure.

\section{Application and development of 3D design in substation engineering}

The 3D digital technology is applied in substation engineering design and establish a unified digital management platform, through the integrated application of geographic information system, 3D modeling, digital collaborative design, digital handover and construction fine management, the design and construction can be visualized and intelligent, and the engineering data and information can be Shared in multiple stages, so as to serve the full life cycle management of power grid engineering. The development direction of $3 \mathrm{D}$ design of substation engineering is embodied in three aspects: integration of geographic information, integration of data model and application of results.

\subsection{Integration of geographic information}

With the integration of multiple geographic information system, the system can include the geographical spatial data, spatial data grid, the grid data, slop area project data, hydrological information[3], etc., through 3D visualization and information technologies, support for substation site selection, station surrounding environment assessment and bulk transport scheme, etc.

\subsection{Data model integration}

Multi-dimensional data model is the core and foundation of digital 3D design and whole-life management of substation. Based on the three-dimensional model, it loads the basic information of equipment and materials, such as quantity, parameters and technical specifications, interrelationship between models, relationship with external environment, and timing relationship, etc[4].The multidimensional data model can be continuously enriched with the gradual development of design, construction, operation and maintenance, etc., and can be endowed with more detailed data information in the construction, production, operation and maintenance stages.

\subsection{The whole process of application}

In the design review stage, give full play to the ability of analyzing, mining and utilizing big data in the review process of substation engineering, build a three-dimensional review and management platform of substation engineering, realize the visualization of 
multi-dimensional scene based on big data, and improve the efficiency and level of review.

In the construction stage, the 4D construction project management method based on 3D design technology, which can be adopted to associate the 3D design model of substation with the time schedule plan, so as to realize the refined control and control of the construction process, resource planning, schedule management, risk management and other aspects.

In the operational phase, the use of $3 \mathrm{~d}$ design, according to the operation monitoring system of substation equipment on-line real-time data, which can realize 3D visualization way of monitoring the operating state of transformer substation equipment and dynamic data, and focusing on space position information of substation, the equipment maintenance records of main design parameters, patrol and state information of equipment operation, implement the visualization operations of the substation.

\section{Conclusions}

The 3D design technology of substation engineering is an integrated innovation of modeling technology, information technology and network technology in the field of design. The adoption of collaborative design mode based on 3D design and real-time information interaction is conducive to the optimization of engineering scheme and the effective improvement of engineering design quality and efficiency. The visualized and refined $3 \mathrm{D}$ models and drawings provided by $3 \mathrm{D}$ design can meet the overall digital handover requirements of design results and realize multi-link sharing, which is conducive to improving the level of engineering construction and operation and maintenance management, and laying a solid foundation for the construction of digital power grid and promoting the full life cycle management of power grid.

\section{References}

1. Qie Xin, Qi LiZhong, Hu Junhui. (2012) Application of 3D digital technology in power transmission and transformation engineering. Power Grids and Clean Energy,28(11):23-26.

2. Liu Qing, Wang jianping. (2010) Research on life cycle management of Construction Project based on BIM technology. Civil and architectural engineering information technology,2(3):40-45.

3. Huang peng, Jin huan, Ma xiao, etc.(2015) Application of 3D GIS technology in transmission line Selection. Electrical Engineering,16(3): 125-128.

4. Li sihao. (2018) Research on the application of digital 3D design in substation Engineering. Electrical Engineering, (3): 103-108. 